\title{
After Action Report: Specific Manufacturing Capability \\ 2015 Evaluated Drill September 23, 2015
}

October 2015

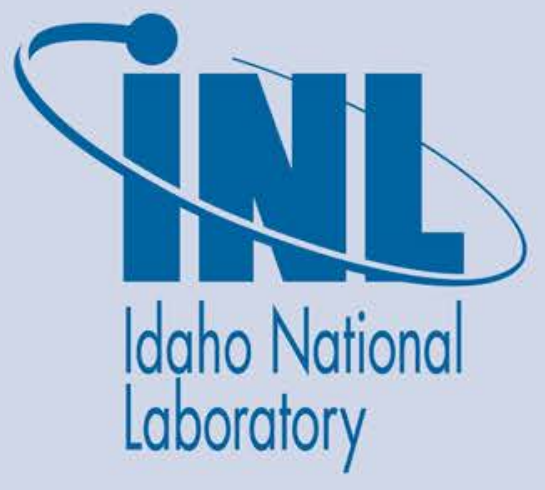

The INL is a U.S. Department of Energy National Laboratory operated by Battelle Energy Alliance 


\section{DISCLAIMER}

This information was prepared as an account of work sponsored by an agency of the U.S. Government. Neither the U.S. Government nor any agency thereof, nor any of their employees, makes any warranty, expressed or implied, or assumes any legal liability or responsibility for the accuracy, completeness, or usefulness, of any information, apparatus, product, or process disclosed, or represents that its use would not infringe privately owned rights. References herein to any specific commercial product, process, or service by trade name, trade mark, manufacturer, or otherwise, does not necessarily constitute or imply its endorsement, recommendation, or favoring by the U.S. Government or any agency thereof. The views and opinions of authors expressed herein do not necessarily state or reflect those of the U.S. Government or any agency thereof. 


\title{
After Action Report: Specific Manufacturing Capability 2015 Evaluated Drill September 23, 2015
}

October 2015

Idaho National Laboratory Idaho Falls, Idaho 83415

\author{
http://inl.gov
}

\section{Prepared for the}

U.S. Department of Energy

Under DOE Idaho Operations Office

Contract DE-AC07-05ID14517 
This page intentionally left blank. 


\section{Emergency Management}

\section{After Action Report: Specific Manufacturing Capability 2015 Evaluated Drill September 23, 2015}

INL/EXT-15-37029

Revision 0

October 2015 
This page intentionally left blank. 


\section{CONTENTS}

ACRONYMS

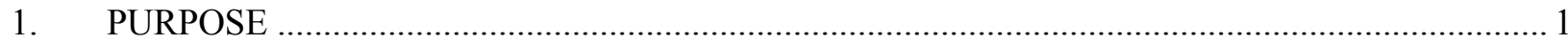

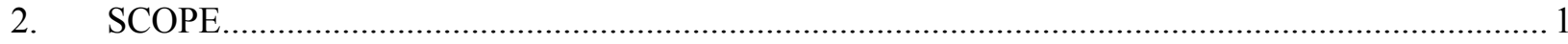

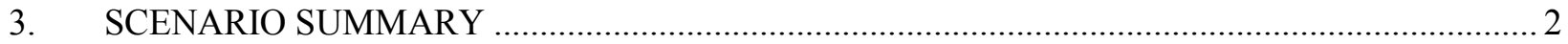

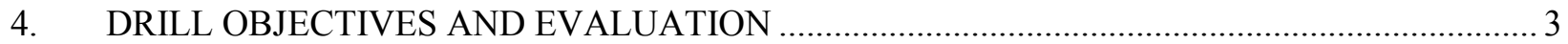

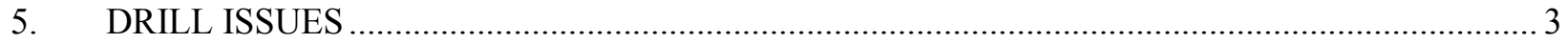

5.1 Emergency Response Organization Response ................................................................ 3

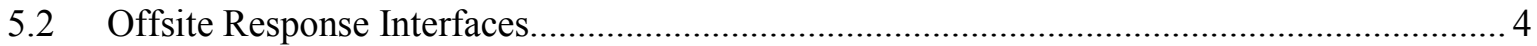

5.3 Emergency Event Categorization and Classification ................................................... 4

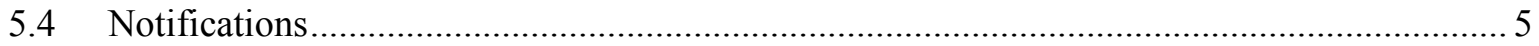

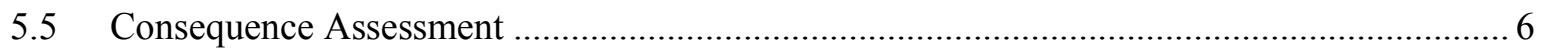

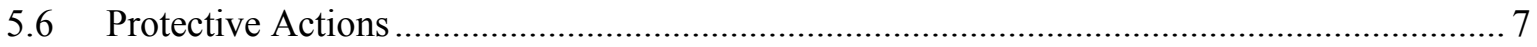

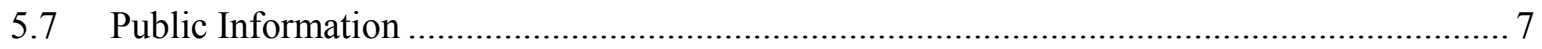

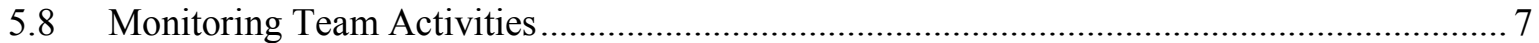

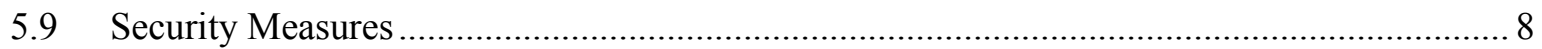

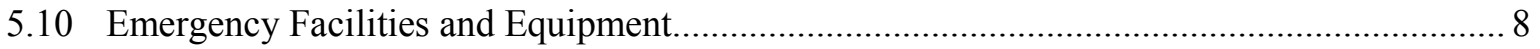

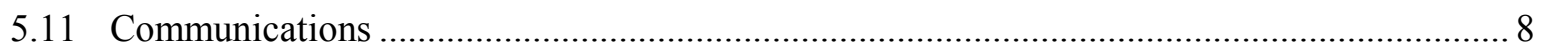

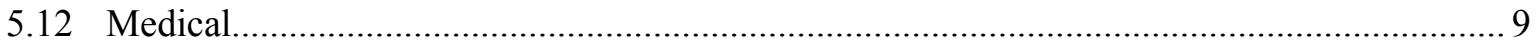

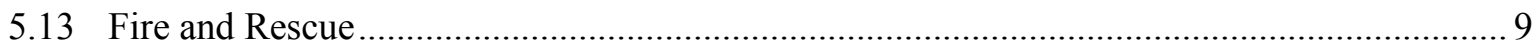

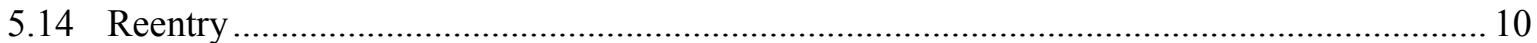

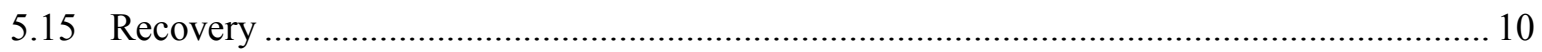

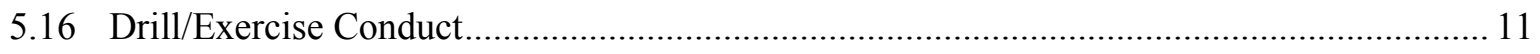

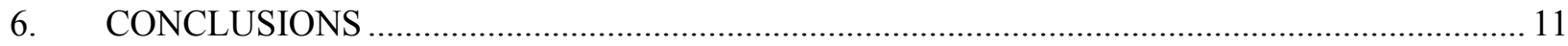

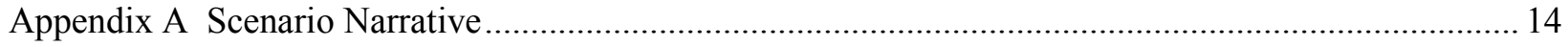

TABLES

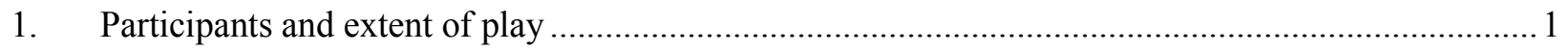

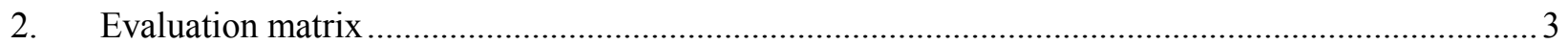




\section{ACRONYMS}

CFA Central Facilities Area

DOE Department of Energy Idaho

DOE-ID Department of Energy Idaho Operations Office

EAL emergency action level

EAM emergency action manager

ECC emergency control center

ED emergency director

EOC emergency operations center

ERO emergency response organization

FAC Fire Alarm Center

FD Fire Department

INL Idaho National Laboratory

JIC Joint Information Center

OE operational emergency

PAs protective actions

SMC Specific Manufacturing Capability

SS shift supervisor

TAN Test Area North

WCC Warning Communications Center 
This page intentionally left blank. 


\section{After Action Report: Specific Manufacturing Capability 2015 Evaluated Drill September 23, 2015}

1. PURPOSE

On September 23, 2015, the Specific Manufacturing Capability (SMC) facility, operated by Battelle Energy Alliance LLC at Idaho National Laboratory (INL), in coordination with other INL organizations conducted an evaluated emergency drill to demonstrate the ability to respond to and mitigate an operational emergency (OE) per the requirements of DOE O 151.1C, "Comprehensive Emergency Management System," the Emergency Management.

\section{SCOPE}

Participants and their extent of play are shown in Table 1.

Table 1. Participants and extent of play.

\begin{tabular}{|c|c|}
\hline Participants & Extent of Play \\
\hline \multicolumn{2}{|c|}{ INL Organizations } \\
\hline $\begin{array}{l}\text { Central Facilities Area (CFA) Emergency Control } \\
\text { Center (ECC) }\end{array}$ & Limited: control cell \\
\hline INL Emergency Operations Center (EOC) & Full participation \\
\hline INL Fire Alarm Center (FAC) & Full participation \\
\hline INL Fire Department (FD) & Full participation \\
\hline INL Joint Information Center (JIC) & Full participation \\
\hline INL Medical & Limited: control cell \\
\hline INL Security & Full participation \\
\hline Specific Manufacturing Capability (SMC) ECC & Full participation \\
\hline Warning Communications Center (WCC) & Full participation \\
\hline \multicolumn{2}{|c|}{ Contiguous Counties } \\
\hline Bingham & Limited: notifications only \\
\hline Bonneville & Limited: notifications only \\
\hline Butte & Limited: notifications only \\
\hline Clark & Limited: notifications only \\
\hline Jefferson & Limited: notifications only \\
\hline \multicolumn{2}{|c|}{ Federal Agencies } \\
\hline $\begin{array}{l}\text { Department of Energy Idaho Operations Office } \\
\text { (DOE-ID) }\end{array}$ & Full participation \\
\hline
\end{tabular}


Table 1. (continued).

\begin{tabular}{|l|l|}
\hline \multicolumn{2}{|c|}{ State of Idaho Agencies } \\
\hline Idaho State Communications Center & Limited: notifications only \\
\hline Idaho State Police & Limited: notifications only \\
\hline INL Oversight Program & Limited: notifications only \\
\hline \multicolumn{2}{|c|}{ Tribal Authority } \\
\hline Shoshone/Bannock Tribe & Limited: notifications only \\
\hline
\end{tabular}




\section{SCENARIO SUMMARY}

\section{Background}

Normal operations are being conducted at SMC. It is simulated that an employee operating a Wiggins' forklift with 8' long tines east of TAN-681 has an apparent heart attack. The employee feels excruciating pain in his chest and inadvertently presses down on the accelerator driving the forklift into the east side of TAN-681, running through the exterior wall of the building and into one of the process tanks inside. Another employee walking inside the building is struck by some of the building material and knocked down. The forklift tines puncture the tank releasing liquid material containing depleted uranium to the surrounding area. The forklift operator strikes his head on the steering wheel and becomes momentarily unconscious. One employee in the area assists the forklift operator off the forklift. Inside the building an employee upon hearing the noise from the wreck, turns and see the injured employee inside the building and assists him outside. During the course of removing the injured employee, both individuals come in contact with the liquid from the tank that contains depleted uranium.

\section{$\underline{\text { Drill Start }}$}

Personnel pull a manual fire alarm. The FD and the SMC nurse responds to the area and find the forklift operator and begin to treat the injured forklift operator and prepare him for transport. The forklift operator is simulated as being transported to a local hospital for further treatment and evaluation. The injured employee from inside the building and the one that helped him from the area will be found to be contaminated with the material from the tank on their clothing, but nasal swabs are negative. The second injured employee has some bruising and minor scratches and kept for observation. Decontamination of personnel activities will be walked through.

The SMC Emergency Action Manager (EAM) activates the SMC emergency response organization (ERO), verifies accountability, protective actions (PAs), and categorizes and/or classifies the event using the SMC facility emergency action levels (EALs). Initial off-site notification is completed with all follow-up notifications being simulated.

The CFA ECC, EOC, and JIC are declared operational.

The emergency director (ED) and the CFA EAM receive a briefing from the SMC EAM. The ED accepts categorization/classification, notifications, and PAs. EOC personnel conduct an initial consequence assessment based on real weather and a worst-case scenario. After receiving additional facility data from the SMC ECC, the EOC planning team conducts additional consequence assessments.

Responders and ERO personnel will discuss corrective actions including reentry planning. If it is determined that reentry planning is needed, the SMC ECC, in coordination with the FD and the EOC, will initiate the development of an initial reentry plan with consideration given to the risk versus benefit of making a reentry. Any reentries will be simulated. If it is determined reentry is not required, emergency event termination will be discussed with participants using applicable procedures. Once termination of the emergency has been agreed on, the ED and DOE-ID MDO concurrence given, and a recovery manager has been appointed, the emergency will be terminated. When the drill director has concurrence from the other lead controllers that the objectives of the drill have been completed or at least attempted, the drill is terminated and critiques are conducted and documented. 


\section{DRILL OBJECTIVES AND EVALUATION}

NOTE: Only the SMC ERO was formally evaluated during the drill. All other player organizations were conducting a training evolution.

During the drill, 13 of the 16 standardized INL objectives were evaluated for SMC using the appropriate demonstration criteria. Twelve objectives were rated satisfactory and one was rated as a weakness.

The ratings in Table 2 are based on the issues that follow in Section 5 of this report.

Table 2. Evaluation matrix.

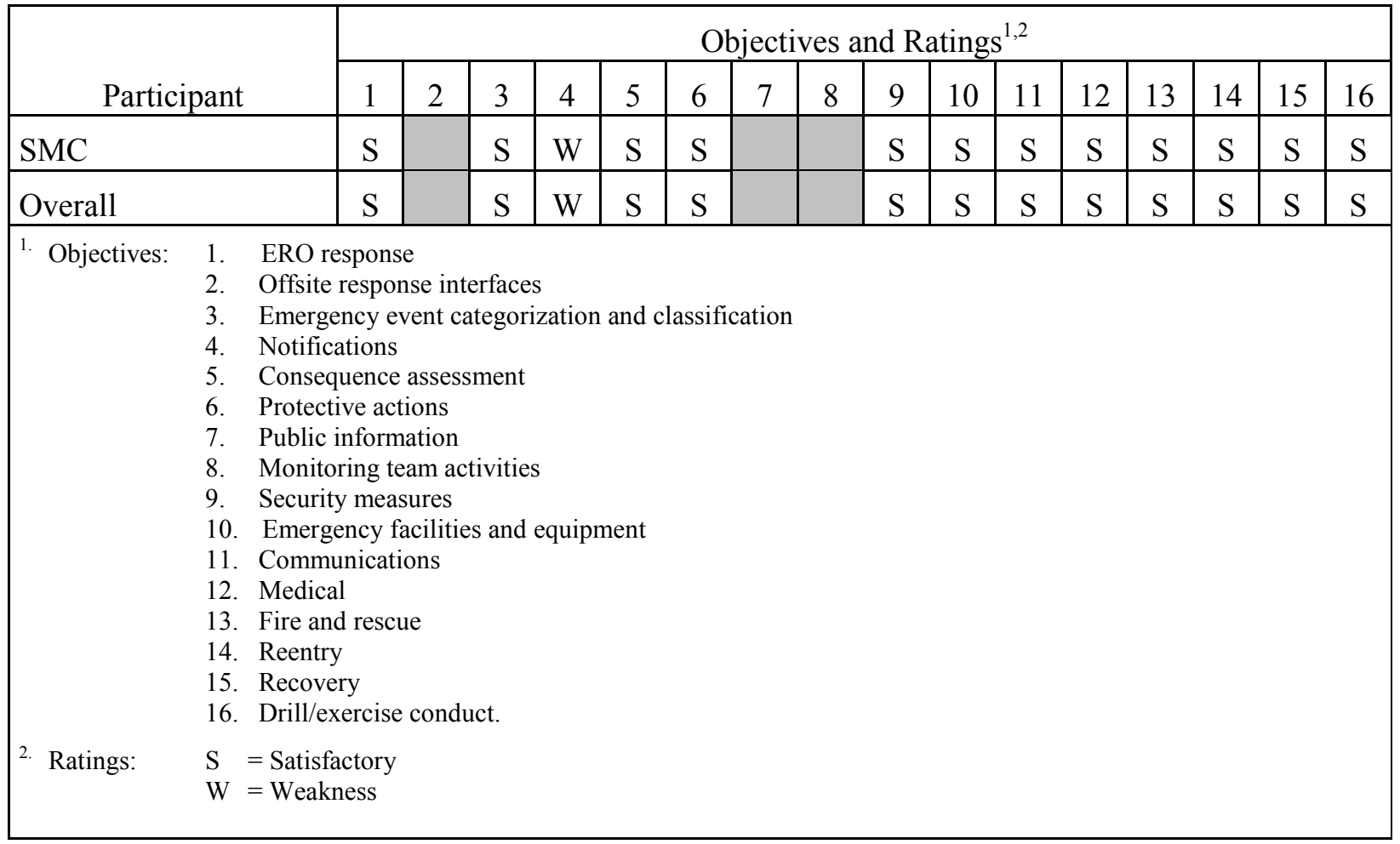

\section{DRILL ISSUES}

The following issues are specific to the evaluation of SMC ERO. Each item has been evaluated and entered into the appropriate issues management system.

\subsection{Emergency Response Organization Response}

Given the facility procedures/plan, the ERO will respond to, monitor, and evaluate the specific indicators of an emergency for mitigation of the consequences and bring the emergency situation under control.

\section{Discussion}

The drill was initiated with a manual fire alarm being activated. The Fire Alarm Center (FAC) dispatched the appropriate resources to the event area. SMC security personnel made applicable voice announcements notifying SMC personnel of the response. The FD arrived on scene, as did the shift supervisor (SS). Event information was provided to SMC management including the on-duty EAM. The SMC EAM determined to activate the SMC ERO, which was done at 1326 hours by voice announcement. A follow-up call was made to the Warning Communications Center (WCC). WCC personnel activated the 
EOC, and the JIC and the CFA ECC being a control cell. All equipment used for activation of the ERO and notification to the general population at SMC functioned properly.

SMC ERO personnel arrived in a timely manner, activated their respective positions according to procedures and checklists, and opened and maintained their logs. Communications were established with the Incident Command Post. During the drill, an effective turnover happened between the SS and the incident communicator. As the SMC ECC met staffing requirements, the ERO team was briefed on the event, and the ECC was declared operational at 1337 hours. The assistant EAM notified WCC of the declaration. Information continued to be gathered on the event, which allowed the ERO to analyze the event and assist with mitigation of the event.

Lines of communication were established between the activated ERO elements with information being provided to keep the other EROs updated. This included command bridge briefings conducted between the SMC EAM, ED, and CFA EAM.

Effective direction and control was demonstrated throughout the event. At SMC, two qualified EAMs arrived with one taking the EAM responsibilities and the other stepping back and assisting throughout the event by monitoring activities, reviewing the EAM checklist, and effectively keeping the big picture in mind. The EAM assigned tasks and followed them through to completion. Priorities were established with specific personnel assigned to track various event tasks and provide statuses. The SMC EAM provided timely briefings throughout the event and kept the ERO team focused on the task at hand. Though not part of the evaluation of this drill, it was noted the ED effectively demonstrated command and control in the EOC during the event.

In summary, ERO personnel used their knowledge of the affected facility, its operations, and the operations of the ECC to effectively respond to, monitor, and evaluate event indicators that enabled the team to successfully mitigate consequences of the event and bring the situation under control.

$\underline{\text { Issues }}$

- None.

\subsection{Offsite Response Interfaces}

Given the facility procedures/plan, the ERO will coordinate and interface with response organizations to protect the environment and health and safety of the public.

\section{Discussion}

- Not evaluated in this drill.

\subsection{Emergency Event Categorization and Classification} OE.

Given the facility procedures/plan, the ERO will accurately and promptly categorize and classify the

\section{Discussion}

The SMC on-duty EAM, along with other ERO personnel, responded to the SMC ECC at 1327 hours, and using the information that they knew at the time, accurately and promptly categorized the event as a classified $\mathrm{OE}$ in accordance with applicable procedures and within time requirements.

The SMC EAM used his knowledge of the facility and the event, reviewed the EALs with the other SMC EAM, and identified the correct EAL, SMC-681-4.A.1, and made the declaration at 1330 hours, which is within the 15 minutes of recognition of a classified OE. During the review of the EALs, ERO personnel demonstrated an understanding of the EAL layout within the procedures.

Additional EALs were reviewed to determine what other conditions could occur that might lead to a different EAL. Personnel agreed that if a fire occurred, the event would have to be reclassified as a site 
area emergency. The EAM directed actions that would help eliminate ignition sources reducing the likelihood of a fire occurring. The ERO then continued to monitor the emergency event for changes and applicability to the EALs.

During a command bridge briefing, the categorization and classification function was effectively transferred to the ED following applicable procedures and protocols.

\section{$\underline{\text { Issues }}$}

- None.

\subsection{Notifications}

Given the facility procedures/plan, the ERO will report emergencies and conduct follow-up notifications to the appropriate organizations within the required time.

\section{Discussion}

The notification process was initiated at SMC in a timely manner. The SMC emergency planner began the process using the correct form, and was relieved by the SMC notification specialist shortly after. The initial notification form was completed, reviewed, and approved by the SMC EAM and faxed to the WCC for transmittal to off-site agencies and on-site facilities.

The initial notification form was completed in a timely manner and faxed to the WCC eight minutes after the event was declared a classified OE. Verification that the WCC had received the initial notification form was made. Approximately seven minutes after the SMC notification specialist faxed the form, he contacted the WCC again, and they indicated they had problems with the automated notification system and were not able to make notifications. The SMC emergency planner and the SMC notification specialist then began using EPI-9, "Emergency Event Notifications," to determine how to make offsite notifications manually. They contacted WCC and were told WCC was already in the process of doing notifications manually. Notifications were officially made at 1357 hours, twenty-seven minutes after declaration missing the fifteen-minute time requirement.

A review of the initial notification form indicated there was an error in block 5 . The box that was checked indicated the event was an unclassified event even though the EAL identified the event as an Alert, which is a classified OE. This mismarking also led to some confusion on the time requirement for completion of notifications later on when the WCC had equipment problems while making notifications. Because the wrong box was checked, the notification specialist announced they should still be able to meet the notification time requirement since they had 30 minutes to complete notifications. Additionally block 7 was not completed and block 8 was partially completed.

The first follow-up notification was completed and submitted at the same time as the transfer of the notification functions was occurring. A review of the form submitted by SMC ERO personnel indicated the same inaccuracies were transcribed from block 5 of the initial form to block 6 of the follow-up form. Additional inaccuracies were made regarding the release information on the two subsequent follow-up notification forms. On message form No. 2, box 11 was not completely filled out. On notification form No. 3, box 11 was only partially completed and with inaccurate information, and block 13 was completed incorrectly.

During the first command bridge briefing, the SMC EAM effectively transferred the notification, categorization/classification, and protective functions to the ED.

\section{$\underline{\text { Issues }}$}

- Issue 5.4.1: Inattention to detail when completing offsite notification forms. Several errors were identified on the initial notification form and the two subsequent follow-up notification forms. First, the incorrect box in block 5 of Form 150.06, "INL Initial Emergency Notification Form" was 
checked. The box checked indicated the event was an unclassified OE while the EAL listed indicated the event was a classified event at the Alert level. This caused some confusion as to what the time requirements were for completing notifications for the event. Additionally, this could have caused confusion to on-site response organizations, other ERO teams, and off-site agencies as to whether the event was a classified event or not. This erroneous information was carried onto the second follow-up notification form and corrected on the third follow-up notification form. Additional inaccuracies were made regarding release information on both follow-up notification forms. On the first follow-up form, box 11 indicated a release had happened and been stopped yet the rest of the box was not completed. On the second follow-up notification form, it indicated that no release was expected while box 5 of the same form indicated a release had occurred and box 13 indicated the material was on the "extremely hazardous material" list, which it is not.

\section{Recommended corrective action:}

- Issue 5.4.1- Provide lessons learned information/training stressing the importance to paying attention to the details when completing/reviewing/approving off-site notification forms by conducting a review of this issue with personnel who complete/review/approve notification forms using the examples listed. A review of the EAL identification number system should be included during this review of forms 150.06 and 150.06A, "INL Follow-Up Emergency Notification Form." Laboratory Protection LabWay No. LP-CO-2015-1887 assigned.

- Issue 5.4.2: Offsite notification time requirements were not met because WCC had problems with their automated notification system. Laboratory Protection LabWay No. LP-CO-2015-1888 assigned.

\subsection{Consequence Assessment}

Given the facility procedures/plan, the ERO will assess actual and potential onsite and offsite consequences of an emergency.

\section{Discussion}

Using facility procedures and processes, the ERO utilized default data and facility data to assess actual and potential on-site and off-site consequences during this drill.

An initial assessment of consequences of the emergency was made utilizing default information contained in the EALs. This process allowed for verification that the event had been categorized and classified correctly, PAs were adequate, and allowed for informative decision-making, and projections of on-site and off-site consequences.

As more information became available through the planning bridge and from information contained on the consequence assessment data form submitted from the facility, monitoring and evaluation of event conditions was performed to continually assess the consequences of emergency event and to monitor safety, health, environmental, and security conditions that may affect the emergency. Neither the hazard survey nor the hazard assessment documents are available in the EOC for this facility because some of the information is classified. This made the consequence assessment team have to make determinations based on the limited information that was available. In doing so, a good questioning attitude was demonstrated by the consequences assessment team in the EOC as they tried multiple ways to determine if there were other constituents in the liquid spilled on the floor of the building that would be of concern. They determined that the depleted uranium was the biggest health hazard and responded accordingly.

Consequence assessment results were effectively communicated as necessary to enhance the mitigation activities.

Issues

- None. 


\subsection{Protective Actions}

Given the facility procedures/plan, the ERO will respond to emergency conditions to protect onsite personnel and the public by implementing specific, predetermined actions.

\section{Discussion}

A manual fire alarm was activated at the emergency egress door. All personnel evacuated the associated buildings and reported to the assembly area. The accountability process began with the area wardens conducting building sweeps on their way out. Once the SMC ECC was activated, the personnel accountability leader began verifying that all personnel that had carded into the affected buildings. The injured personnel that were participating in the drill were identified as missing, and the ERO quickly verified the location of the missing.

The SMC EAM and the assistant EAM reviewed the EALs and when the correct EAL was identified, the associated PAs were identified and implemented. When the SMC EAM recognized that the PA distance ran through some of the buildings, he suggested that rather than trying to move personnel to different corners or areas of the affected buildings, it would be more prudent to evacuate all of the SMC facility to the SMC cafeteria, which is located outside of the isolation area. Evacuation routes were identified and agreed on. The voice announcement providing directions to SMC personnel was simulated by the EAM by having him explain how he would implement the PAs. Implementation of the evacuation was then simulated. A determination was made on how many additional evacuation buses were made and requested through the CFA ECC.

Transfer of the PA/protective action recommendations to the ED was successfully demonstrated by the SMC EAM and the ED.

\section{Issues}

- None.

\subsection{Public Information}

Given the facility procedures/plan, the ERO will demonstrate an emergency public information program.

\section{Discussion}

Public information personnel in the EOC were able to monitor the event, gather information and develop media releases for review and approval by the required personnel in the EOC, and then provide them to the JIC for dissemination.

The JIC was activated with the EOC. The JIC was declared operational in a timely manner. Actors portraying other news agencies, family members, and concerned persons called into the JIC requesting event information. The JIC successfully demonstrated their ability to handle questions and address concerns.

$\underline{\text { Issues }}$

- None.

\subsection{Monitoring Team Activities}

Given the facility procedures/plan, the ERO will provide facility/site monitoring teams in support of consequence assessment activities.

\section{$\underline{\text { Issues }}$}

- Not evaluated in this drill. 


\subsection{Security Measures}

Given the facility procedures/plan, Security will respond to, monitor, and evaluate the specific indicators of an emergency for mitigation of the consequences and bring the emergency situation under control.

\section{Discussion}

SMC security personnel made applicable voice announcements alerting personnel of the arrival of the FD. They responded to the event area and established communication with the incident commander. They established access control around the event and to the facility. A good discussion occurred on how to maintain access control to the event area after the event was terminated.

\section{Issues}

- None.

\subsection{Emergency Facilities and Equipment}

Demonstrate the adequacy of facilities, equipment, displays, and other materials to support emergency operations.

\section{Discussion}

This drill provided an opportunity to successfully demonstrate the adequacy of the necessary equipment to support emergency operations. Equipment used to activate the ERO functioned as designed as did applicable communications systems, display systems, CPUs, notification equipment, and monitoring and plume projection equipment. Initially there was a problem in the EOC with a CPU but it was rectified and response action continued. One of the positive things demonstrated was the new repeater for the radio system at SMC. Several operations and response personnel commented that communications over the radios was a lot clearer than in the past.

ERO personnel used applicable procedures, checklists, and other documentation in their response activities to provide for an effective response to the event conditions. WebEOC functioned properly and was utilized to share event information in an efficient manner.

\section{Issues}

- None.

\subsection{Communications}

Communications capabilities are managed in support of emergency operations to ensure prompt and appropriate flow of accurate information during an emergency. 


\section{$\underline{\text { Discussion }}$}

Communications within the SMC ECC were deemed adequate. As mentioned previously, good command and control was demonstrated throughout the event. The use of repeat backs or three-way communications was successfully demonstrated at the beginning and through most of the drill. They began to relax the use of repeat backs as the event progressed to the point of being used very little such as only repeating back part of the communication. For example, during one command bridge briefing, the transfer of some functions was discussed. The SMC EAM and only requested to transfer one of three functions but the ED restated all three functions to which EAM replied along the lines of, "Yes that's what I meant." When queried later, the EAM said that as soon as he made the request incorrectly, he recognized the error so when the ED restated the request correctly he just replied, "Yes that's what I meant." There were a couple of other instances where things were stated or a task made and the three-way communications were lax. Overall written and verbal communications were effectively demonstrated during this drill, which aided in the mitigation of the event.

$\underline{\text { Issues }}$

- None.

\subsection{Medical}

Given the facility procedures/plan, medical response personnel will respond to, monitor, and evaluate the specific indicators of an emergency for mitigation of the consequences and bring the emergency situation under control.

\section{Discussion}

The FD picked up and transported the SMC nurse to the event scene where she worked effectively with FD emergency medical services personnel to triage, treat, and transport the injured personnel. Information was provided to the control cell located at the CFA Medical Facility where it was relayed to the medical director in the EOC. It did take a little more time than expected for the medical director to receive the names of the injured; but with some additional calls and research, the information was obtained. It was reported that under normal response activities, they would not have picked up the SMC nurse initially on a manual pull of a fire alarm. The nurse would have been sent for after they arrived or picked up by the battalion chief when he arrived.

Emergency Medical Service personnel effectively determined the condition of the injured personnel and utilized available resources and equipment to successfully get the injured the treatment they needed. After doing an initial assessment and based on the vitals of the victims, a determination was made to transport one to the local area hospital and the other person with minor injuries to CFA Medical. One victim was loaded on a gurney and into an ambulance, but all transports were simulated.

\section{$\underline{\text { Issues }}$}

- None.

\subsection{Fire and Rescue}

Given the procedures/plan, fire and rescue responders will respond to an event involving fire or hazardous material, mitigate the consequences, and bring the situation under control.

\section{Discussion}

A manual fire alarm was pulled at the emergency egress door from TAN-681, which alarmed in the fire alarm panel in TAN-679. FD personnel responded to the front door of building TAN-679 where they were met by facility personnel. It took a few minutes for the FD and facility personnel to determine where the event occurred. Once they realized the injured personnel were around the corner, they quickly responded to and triaged, treated and transported the injured personnel. 
Once the injured were taken care of, they were able to respond to the event area where the forklift had driven it's tines through the building. In consultation with facility operations personnel, they effectively plugged the holes in the side of the building preventing the spread of hazardous material to outside of the building.

FD personnel reported to the SMC ECC and assisted in determining whether or not to make a reentry. They also were instrumental in providing event information in determining if the emergency response could be terminated and allow for event remediation to occur under the recovery phase.

\section{$\underline{\text { Issues }}$}

- None.

\subsection{Reentry}

The ERO will demonstrate development and implementation of a reentry plan to include debriefing of the reentry team and proper recordkeeping in accordance with the facility procedures/plan.

\section{$\underline{\text { Discussion }}$}

Reentry planning was discussed at the scene and in depth in the SMC ECC. The reentry procedure was reviewed and a good discussion to determine if a reentry was necessary occurred. Participants included FD personnel, SMC operations personnel, and ERO personnel. During the discussion in the ECC, a determination was made to not make a reentry based on several things such as the risks versus benefits, the condition of the facility itself, how much liquid would drain and where the liquid would drain to, and the precautions that had been taken such as isolating power to the building and plugging the holes in the exterior wall to prevent the release of material to the outside of the building. When it was decided a reentry would not be made, termination of the event ensued. The SMC EAM went through the applicable step for termination addressing each and asking questions to verify event conditions were such that the emergency could be terminated. ERO personnel, FD, security, and the DOE-ID facility representative all concurred that they were ready to terminate the emergency. Emergency event termination was requested of the ED. The ED and the DOE-ID management duty officer concurred that the emergency event could be terminated.

\section{$\underline{\text { Issues }}$}

- None.

\subsection{Recovery}

Given the facility procedures/plan, the ERO will demonstrate recovery planning for an emergency at the affected facility.

\section{Discussion}

SMC ERO team members used EPI-80, "Recovery" to move into the recovery phase of the event. A recovery manager was identified, which happened to be the on-duty SMC EAM so a formal turnover was not needed. The EAM went through the recovery procedure with the SMC ERO team using appendix A to make sure the necessary event information was captured.

\section{Issues}

- None. 


\subsection{Drill/Exercise Conduct}

Write, conduct, and evaluate a drill/exercise that will emphasize facility-specific emergency events and response activities and minimize the use of generic, nonspecific simulations in accordance with the facility procedures/plan.

\section{$\underline{\text { Discussion }}$}

A successful evaluated drill was conducted to demonstrate the ability of the SMC ERO to effectively respond to and mitigate an operation emergency scenario. The scenario was well written and represented a real plausible event with realistic conditions.

Sufficient controllers and evaluators were strategically placed in appropriate areas to provide direction and control as provided for in the drill package. Controllers only injected the pertinent information when earned by the responders or if specifically identified in the drill package. Evaluators were utilized to evaluate response actions.

Simulations for this drill were held to a minimum providing the necessary information for responders to respond as realistic as possible.

A hot wash critique was conducted with SMC ERO personnel that allowed them adequate time and opportunity to provide feedback on the response of the ERO.

\section{Issues}

- None.

\section{CONCLUSIONS}

SMC ERO personnel successfully demonstrated their ability to effectively respond to and mitigate an emergency situation. The EAM demonstrated effective command and control during the event.

Categorization and classification was determined and declared within the fifteen minute time requirement. PAs were quickly determined and implemented using a conservative approach by evacuating all of SMC to the cafeteria. Effective evacuation routes were determined prior to the evacuation being implemented.

The notification process was followed. When the SMC notification specialist had not been contacted by the WCC, he contacted them and asked for the status on completing notifications. When he realized the automated system that the WCC used was not working, he and the SMC emergency planner began to implement the applicable sections in EPI-9, "Emergency Event Notification," to determine how to manually complete notifications. During the review of the procedure, they contacted the WCC and found out that WCC personnel had already began the manual notification process. With the automated notification system not working, the 15 minute time requirement for making notification was not met. Notifications were completed within 27 minutes using the manual process, which requires calling off-site agencies individually.

Consequence assessment was effectively demonstrated throughout the event, which enabled EOC personnel to verify that the correct EAL had been used and that the protective actions were adequate. Public information personnel were able to gather sufficient information to develop media releases and provide information to the JIC for dissemination to the public.

Overall, communications between the scene and the SMC ECC, within the SMC ECC and the EOC and between response facilities was effective. Equipment was available and functioned as designed. Procedures, checklist, and documentation were available and used during this event.

FD and medical response organizations effectively demonstrated their response capabilities by responding to the alarms, information provided on-scene, and other information to triage, treat, and transport the victims. Their expertise was utilized to plug the holes in the exterior wall of the building reducing the likelihood of a release to the outside environment. FD personnel were also involved in 
determining the need for reentry and providing event information to help with the determination to terminate the emergency.

Overall, an effective drill was developed and conducted, which enabled SMC ERO to respond to event conditions, effectively mitigate the consequences of the event, and prepare for the recovery phase of the emergency. 
This page intentionally left blank. 
Appendix A

\section{Scenario Narrative}


This page intentionally left blank. 


\section{Appendix A Scenario Narrative}

\section{Background}

Normal operations are being conducted at SMC. An employee, east of TAN-681, is operating a Wiggins' forklift that has been fitted with 8' long tines. During operations, he has an apparent heart attack. As he feels the excruciating pain in his chest area, he inadvertently presses down on the accelerator. The forklift crashes into the east side of TAN-681 with the tines running through the exterior wall into the building and into one of the process tanks inside of the building. Another employee walking inside the building is struck by some of the building material and knocked down. The forklift tines puncture the tank releasing liquid material from the tank to the surrounding area. The forklift operator strikes his head on the steering wheel and becomes unconscious. One employee in the area assists the forklift operator off the forklift. Inside the building an employee upon hearing the noise from the wreck, turns and see the injured employee inside the building and assists him outside. During the course of removing the injured employee, both individuals come in contact with the liquid from the tank that contains depleted uranium.

\section{Drill Start}

SMC personnel pull a manual fire alarm and/or call the FAC. The INL FD and the SMC nurse responds to the area and find the forklift operator has regained consciousness. They begin to treat the injured forklift operator and prepare him transport. The forklift operator will be simulated as being transported to a local hospital for further treatment and evaluation. The injured employee from inside the building and the one that helped him from the area will be found to be contaminated with the material from the tank on their clothing, but nasal swabs will be negative. The second injure employee will be found to have some bruising and minor scratches and kept for observation. Decontamination activities will be walked through.

The SMC EAM activates the SMC ERO, verifies accountability, PAs, and categorizes and/or classifies the event using the SMC facility EALs. The Initial Emergency Notification Form (150.06 Rev. 08) is submitted to the WCC and initial off-site notification is completed. All follow-up notifications will be simulated as provided to off-site agencies.

The CFA ECC and the EOC are declared operational.

When the simulated backup engine company and HAZMAT team arrive, their entry into the spill area will be simulated.

The ED and the CFA EAM receive a briefing from the SMC EAM. The ED accepts categorization/classification, notifications, and PAs, if transferred. EOC personnel conduct an initial assessment based on real weather and a worst-case scenario. After receiving Form 150.13, "Consequence Assessment Data Form," from the SMC ECC, the EOC planning team conducts additional consequence assessments.

Responders and ERO personnel will discuss corrective actions. If it is determined that the FD will put absorbent on the spill, reentry planning may not be completed. If it is determined reentry is required, the SMC ECC, in coordination with the INL FD and the EOC will initiate the development of an initial reentry plan with consideration given to the risk versus benefit of making a reentry. Any reentries will be simulated.

The SMC EAM appoints a recovery manager.

When all objectives were met, the drill was terminated and critiques were conducted and documented. 